\title{
Assessment of disease managen at community pharmacies through simulated visits in Pakistan
}

\author{
Azhar HUSSAIN, Mohamed I. IBRAHIM, Madeeha MALIK
} Received (first version): 1-May-2013 Accepted: 27-Nov-2013

\begin{abstract}
${ }^{*}$
Objective: The study aimed to document the state of insomnia management at community pharmacies in Pakistan.

Methods: A cross-sectional study was conducted at randomly selected 371 pharmacies in three cities of Pakistan. Simulated patient visits were performed to collect information on case management of insomnia in terms of history taking and patient counseling at community pharmacies. The data was coded, entered and analyzed by using SPSS Version 16. Kruskal-Wallis and Mann Whitney tests $(p<0.05)$ were performed to find out differences. Results: The patients were mainly handled by salesman $83.8 \%(n=311)$, by pharmacist $3.5 \%$ $(n=13)$ and pharmacy assistants $12.7 \%(n=47)$. The mean dispensing time was 1.11 minutes $(S D=5.61)$ with the range of $0.5-6$ minutes. Of the 371 simulated patients who visited the pharmacies, $72.8 \%(n=270)$ subjects were given medicines and $24.3 \%(n=90)$ subjects were referred to the doctor for treatment of insomnia. $61.8 \%(n=193)$ of the subjects were given benzodiazepines, $35.6 \%$ $(n=111)$ antihistamines and $2.6 \%(n=8)$ NSAIDs at community pharmacies in the three cities. The mean cost of treatment in case of insomnia was PKR12.7 (SD=10.13, median=10).

Conclusions: The disease management of insomnia by community pharmacies in Pakistan is not appropriate. The overall process of history taking, medication counselling and referral practices at community pharmacies either located in rural or urban setting and irrespective of the provider type and location of pharmacies, in the three cities is limited.
\end{abstract}

Keywords: Sleep Initiation and Maintenance Disorders; Community Pharmacy Services; Professional Practice; Pharmacies; Patient Simulation; Pakistan

\footnotetext{
*Azhar HUSSAIN. BPharm (Hons), PhD. Professor,
} Chairman. Pharmacy Department. Hamdard Institute of Pharmaceutical Sciences, Hamdard University. Islamabad (Pakistan). azharhussain10971@gmail.com

Mohamed Izham IBRAHIM. BPharm (Hons), PhD

Professor of Social \& Administrative Pharmacy. College of Pharmacy, Al Qassim University. Al Qassim (Saudi Arabia).

Madeeha MALIK. BPharm (Hons), M-Phil. Assistant Professor. Pharmacy Department, Hamdard Institute of Pharmaceutical Sciences, Hamdard University. Islamabad (Pakistan).madeehamalik15@gmail.com.

\author{
EVALUACIÓN DE LA GESTIÓN DE LA \\ ENFERMEDAD DE INSOMNIO EN \\ FARMACIAS COMUNITARIAS A TRAVÉS \\ DE VISITAS SIMULADAS EN PAKISTÁN
}

\section{RESUMEN}

Objetivo: El estudio trato de documentar el estado de la gestión del insomnio en farmacias comunitarias en Pakistán.

Métodos: Se realizó un estudio transversal en 371 farmacias aleatoriamente seleccionadas en tres ciudades de Pakistán. Se realizaron visitas de pacientes simulados para recoger información sobre la gestión del insomnio en relación a recogida de historia y asesoramiento del paciente en farmacias comunitarias. Los datos fueron codificados, introducidos y analizados en un SPSS versión 16. Se realizaron tests de Kruskal-Wallis and Mann Whitney $(\mathrm{p}<0.05)$ para determinar diferencias. Resultados: Los pacientes eran fundamentalmente atendidos por un vendedor $83,8 \%(n=311)$, por farmacéuticos $3,5 \%(n=13)$ y auxiliares de farmacia $12,7 \%(n=47)$. La media de tiempo de dispensación fue de 1,11 minutos ( $\mathrm{SD}=5,61)$ con un rango de 0,5 - 6 minutos. De los 371 pacientes simulados que visitaron las farmacias, el $72,8 \%(n=270)$ recibieron los medicamentos y el $24,3 \%(n=90)$ fue remitido al médico para tratamiento del insomnio. El 61,8\% (n=193) recibió benzodiacepinas, el $35,6 \%(n=111)$ antihistamínicos y el 2,6\% $(n=8)$ AINEs en las farmacias comunitarias de las tres ciudades. El coste medio del tratamiento para el insomnio fue de 12,7PKR (SD=10,13; mediana=10).

Conclusiones: La gestión del insomnio en farmacias comunitarias de Pakistán no es apropiada. El proceso general de recogida de historial, asesoramiento sobre medicación y remisión al médico en las farmacias comunitarias es pobre tanto en farmacias rurales como en las urbanas, y es independiente del proveedor y de la localización de las farmacias en las tres ciudades.

Palabras clave: Trastornos del Inicio y del Mantenimiento del Sueño; Servicios de farmacias comunitarias; Ejercicio profesional; Farmacias; Simulación de Paciente; Pakistán

\section{INTRODUCTION}

Insomnia, the inability to sleep, is a common concern of the society at present. Approximately, one third person from the population of the world 
suffers from one or more symptoms of insomnia, and about $10 \%$ fulfill the criteria for a clinical diagnosis. ${ }^{1}$ Drug-use, long-term sick-leave, major depression and hypertension are few of the factors related with insomnia which lead to substantial individual suffering and costs to society. ${ }^{2,3}$ Selfmedication is a common practice for the treatment of insomnia. ${ }^{1}$ Sedating antihistamines and herbal sleep promoting products are the only products available without prescription that are approved for insomnia treatment. ${ }^{4,5}$ However, several studies highlighted the use of alcohol and over-the-counter (OTC) sleep aids more frequently by insomniacs to self-medicate. ${ }^{1,6}$ In the current health care scenario, community pharmacies are looked upon for their potential in disease management, which requires knowledge and skills of the dispensers in the treatment of common ailments and their understanding of patient referral. Pharmacists have an important role in screening sleep disorders such as insomnia and providing sleep health education. Implementing individual counselling and treatment recommendations for insomnia can help to reduce the burden of disease and the risks of potential consequences. ${ }^{7}$ In a study concerning pharmacies in Australia, pharmacists providing medicines to treat obstructive sleep apnea, stated that they believed they should have an increased role in the treatment of sleep disturbances such as insomnia. ${ }^{8}$ But, in developing countries, due to lack of qualified personnel, direct access to pharmacists in all the areas is not possible. Thus, the quality of pharmaceutical services in a given region becomes dependent on the availability of a pharmacist. It is a well-known fact that the conditions of pharmacy practice differ among countries and also vary between different areas within the same country. This is due to the number of pharmacists being lower than required. ${ }^{9}$ The dispensers working at community pharmacies in the developing countries do not possess adequate understanding regarding the process of effective disease management, though they are extensively involved in it. ${ }^{10-16}$ They hardly ask questions about the illness, and historical information obtained is inadequate to determine the nature or severity of disease or appropriateness of therapy. ${ }^{17-22}$ Situation is quite similar in Pakistan. There are approximately 63,000 community pharmacies in the country. ${ }^{23}$ They often lack adequate facilities, staffing and equipment. Besides this, the dispensers working at these pharmacies are not trained, and yet, are involved in making diagnoses and recommending therapy to the patients along with dispensing of medicines. There is lack of research and availability of evidence in identifying problems in disease management of common ailments and their counteractive actions at community pharmacies in Pakistan. Therefore, the present research was conducted to document and compare the process of case management for insomnia at community pharmacies in three major areas of Pakistan namely Islamabad (national capital), Peshawar (capital of Khyberpakhtoonkhwa province) and Lahore (capital of Punjab province).

\section{METHODS}

A survey was conducted between April-June 2008. Simulated patient visits were performed to get information regarding case management of insomnia in terms of history taking and patient counseling at community pharmacies. The data collection tool was adopted from WHO manual ${ }^{24}$ "How to investigate drug use in health facilities" and was modified according to the objectives of the study. Focus group discussions were carried out with community pharmacist, drug inspectors, academia and members of consumer groups for finalization of the tool. Face and content validity were built through panel of pharmacy research experts, community pharmacists, statistician and pilot testing. The value of Cronbach's alpha was 0.69 which was applied to assess the reliability and internal consistency of the data.

The observation form included a total of twenty four questions which included history obtained regarding demographics of patients, history of illness, medication and medical history, advice regarding dose, frequency, duration, use and side effects of drug. The above parameters were considered as a minimum standard of case management, however additional information was collected regarding information on provider type, dispensing time, referral, suggestion of remedy, any additional questions asked by the dispenser, advice given by the dispenser and cost of medication.

A case management scale was finalized consisting of two sub scales. Sub scale I included five questions regarding history obtained regarding age, weight, history of illness, medication and medical history. The score was between 6-10 and lower scores referred to better compliance. Sub scale II included five questions regarding dose, frequency, duration, use and side effects of drugs. The score was between 5-10 and lower score referred to better compliance. The above parameters were considered as a minimum standard of history taking and provision of advice. There is no local ethical committee present in the country for the approval of research. However, the concerned drug inspectors of the area were contacted and written approval was obtained to carry out the research. Local chapters of chemist and druggist associations were also approached and informed regarding the research. The study was also approved by Research \& Development wing of Drug Control Organization at Ministry of Health (No. F.2-4/2007DDC (R\&D), Government of Pakistan.

\section{Sampling of pharmacies and respondents}

A comparative, cross sectional study design was used. The total population of community pharmacies in Islamabad and Peshawar were 169 and 170 respectively. Sample size of community pharmacies in Islamabad $(n=118)$ and in Peshawar $(n=120)$ was calculated by using the formula at $95 \%$ confidence interval. ${ }^{25}$ The list obtained from Lahore showed a figure of 3000 premises including pharmacies, distributors and wholesalers, but when discussed with the drug inspectors of Lahore region it was found that the actual number of licensed 


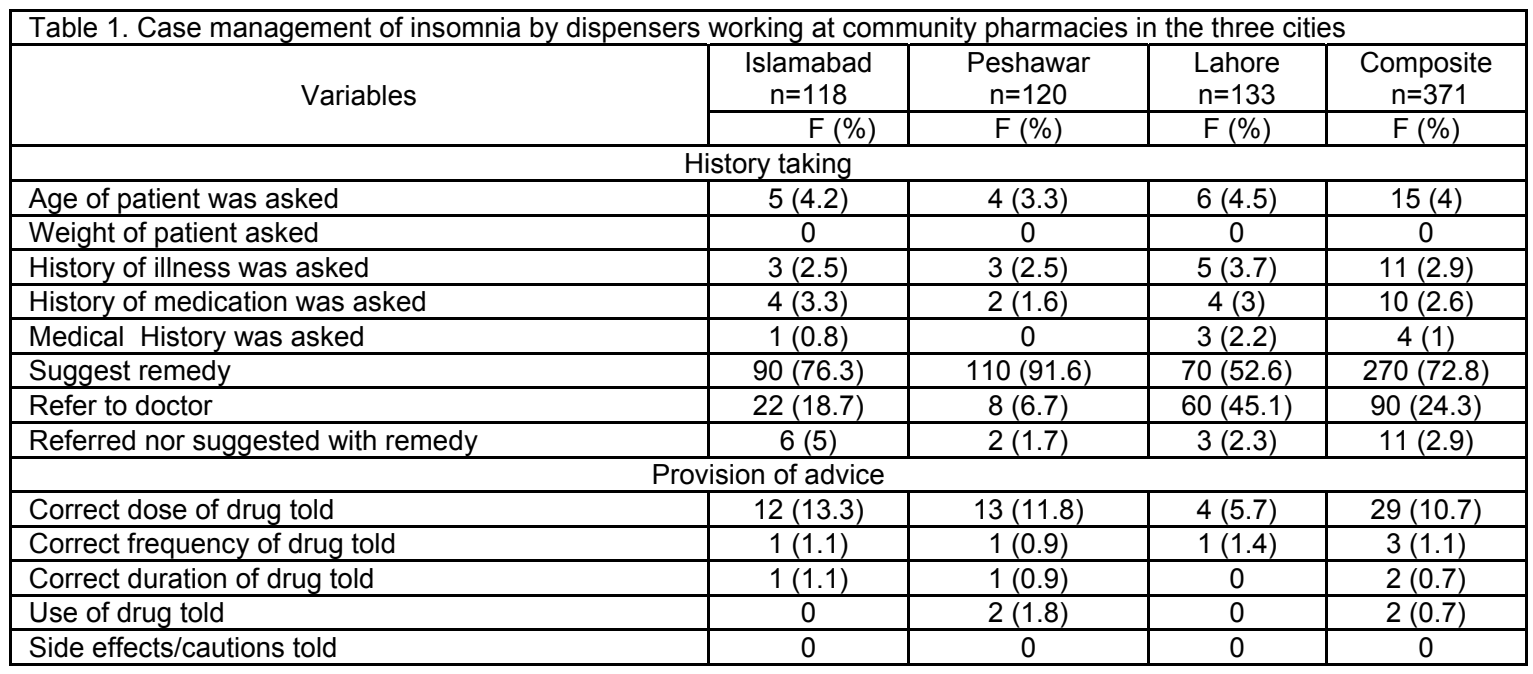

pharmacies was not more than 1000-1200. The reason being, the list was not updated for many years, it also included closed and or shifted premises and also the wholesale and distribution outlets. Keeping in view the above issues, the population of community pharmacies in Lahore was considered as 1100. Sample size of 293 pharmacies was calculated by using the sample size calculation formula at $95 \%$ confidence interval, but due to logistical constraints only 133 pharmacies were visited in Lahore. ${ }^{25}$ A total of 371 simulated patient visits were conducted at randomly selected sample of 371 pharmacies by using convenient sampling technique in the three respective cities namely Islamabad (118), Peshawar (120) and Lahore (133). The study population included all community pharmacy outlets in Islamabad, Lahore and Peshawar cities selling allopathic medicines, or homeopathic or herbal medicines if sold alongside allopathic medicines. Any shop meeting this definition constituted the sampling unit, the sampling element included dispenser and patients/customers visiting these pharmacies.

\section{Data collection}

Data was collected by trained data. Keeping in view the socio cultural diversity in the regions local data collectors was used. The data collectors were students of final year Doctor of Pharmacy program. Data collectors were trained by the group of experts including principal investigator who visited a total of 371 pharmacies. In Islamabad and Lahore data collectors were both male and females however due to the social barriers in Peshawar only male data collectors were engaged. Data collector presented as a patient of insomnia and wanted to buy some drugs to treat the condition. Other then the complaint/symptoms, no information was presented unless asked by the dispenser. The data collectors spoke to the dispensers at the time of the visit and later recorded the encounters at the end of each visit using a structured observation form. They documented any questions that the pharmacy attendant/dispenser asked before making a recommendation, including any discussion on why product was needed and considerations on an alternative therapy/advice, any explanation given about the product finally recommended; and, any advice about how to treat such condition or when to see a doctor. Any product that was finally recommended was purchased in quantities offered. The principal investigator ensured that the observation form from each pharmacy were compiled and labelled with the name of the pharmacy and required demographics. The observation forms were brought back to the principal investigator on the following day.

\section{Data Analysis}

After data collection, data was cleaned, coded and entered in SPSS version 16. Statistical analysis was undertaken to compare case management of insomnia at community pharmacies among independent variables like cities, location of pharmacies and provider type. Kruskal-Wallis test was performed to find out differences at $5 \%$ confidence interval.

\section{RESULTS}

A total of 371 simulated visits for insomnia were carried out at 371 community pharmacies by the simulated patients in Islamabad, Peshawar and Lahore. Out of 371 community pharmacies $31.8 \%$ $(n=118)$ were in Islamabad, $32.4 \% \quad(n=120)$ in Peshawar and $35.8 \%(n=133)$ in Lahore. Of which $77.4 \%(n=287)$ community pharmacies were located in urban areas while remaining $22.6 \% \quad(n=84)$ in rural areas. These community pharmacies were

\begin{tabular}{|l|c|c|c|c|}
\hline Table 2. Total number of drugs dispensed in treated cases of insomnia at community pharmacies in the three cities \\
\hline \multirow{3}{*}{ Drugs dispensed } & \multicolumn{4}{|c|}{ Drugs dispensed in insomnia at community pharmacies } \\
\cline { 2 - 5 } & Islamabad & $\begin{array}{c}\text { Peshawar } \\
\mathrm{F}(\%)\end{array}$ & $\begin{array}{c}\text { Lahore } \\
\mathrm{F}(\%)\end{array}$ & $\begin{array}{c}\text { Composite } \\
\mathrm{F}(\%)\end{array}$ \\
\hline Benzodiazepines & $60(58.8)$ & $88(62.8)$ & $45(64.3)$ & $193(61.8)$ \\
\hline Antihistamines & $40(39.3)$ & $47(33.6)$ & $24(34.3)$ & $111(35.6)$ \\
\hline NSAIDs & $2(1.9)$ & $5(3.6)$ & $1(1.4)$ & $8(2.6)$ \\
\hline Total no of drugs dispensed & $102(100.0)$ & $140(100.0)$ & $70(110.0)$ & $312(100.0)$ \\
\hline
\end{tabular}




\begin{tabular}{|l|c|c|c|c|}
\hline \multicolumn{5}{|c|}{ Table 3. Cost of treatment for insomnia at community pharmacies in the three cities } \\
\hline \multirow{4}{*}{ Indicators } & \multicolumn{4}{|c|}{$\begin{array}{c}\text { Cost of treatment of Insomnia } \\
\text { Pakistani Rupees (USD) }\end{array}$} \\
\cline { 2 - 5 } & Islamabad & Peshawar & Lahore & Composite \\
\hline Mean & $13.2(0.15)$ & $16.2(0.19)$ & $8.0(0.09)$ & $12.7(0.15)$ \\
\hline Standard deviation & 5.9 & 12.0 & 6.9 & 10.1 \\
\hline Median & 10 & 10 & 8 & 10 \\
\hline
\end{tabular}

present in diverse settings including near hospitals $42 \%(n=159)$, in main markets $37 \%(n=137)$ and remaining $20 \% \quad(n=73)$ in small markets. The patients were mainly handled by salesman $83.8 \%$ $(\mathrm{n}=311)$, by pharmacist $3.5 \%(\mathrm{n}=13)$ and pharmacy assistants $12.7 \%(n=47)$. The mean dispensing time was 1.11 minutes $(S D=5.61)$ with the range of 0.5-6 minutes. Of the 371 simulated patients who visited the pharmacies, $72.8 \%(n=270)$ subjects were given medicines $24.3 \% \quad(n=90)$ subjects were referred to the doctor for treatment of insomnia. A detail sketch of case management of insomnia at community pharmacies in the three cities is given in (Table 1).

While case management of insomnia, $61.8 \%$ $(n=193)$ of the subjects were given benzodiazepines, $35.6 \%(n=111)$ antihistamines and $2.6 \%(n=8)$ NSAIDs at community pharmacies in the three cities (Table 2).

The mean cost of treatment in case of insomnia was PKR12.7 (SD=10.13, median=10). A detail sketch of cost of treatment of insomnia is given in (Table 3 ). The conversion rate as of 10th June, 2010 was USD 1= Pakistani Rupees 84

Man-Whitney $U$ test $(p<0.05)$ was used to compare the case management of insomnia at community pharmacies situated in different settings i.e. (Rural/ urban) in the three cities. There was no significant difference $(p<0.05)$ in the case management of insomnia at community pharmacies located in different settings in the three cities (Table 4).

Kruskal-Wallis test was used to compare the case management of insomnia performed by different types of dispensers (e.g. pharmacist, pharmacy assistant and salesman) working at community pharmacies situated at different locations (e.g. near hospital/super market/small market) in the three cities of Pakistan. There was a significant difference $(p<0.05)$ observed in the process of history taking performed by different dispensers (e.g. pharmacist, pharmacy assistant and salesman) while no significant differences $(p<0.05)$ in the provision of advice by these dispensers was observed. Pharmacists were seen more frequently involved in the process of history taking if available at the community pharmacies. On the other hand, there were no significant differences $(p<0.05)$ seen in the case management (history taking and provision of advice) for the treatment of insomnia among community pharmacies situated at different locations (e.g. near hospital/super market/small market) in the three cities (Table 5).

\section{DISCUSSION}

The results of the study revealed that the overall process of case management of insomnia at community pharmacies in Pakistan is not satisfactory. The findings of the study supports the assumption that the community pharmacies in Pakistan have converted into places of medical practice, carried out by untrained dispensers. Similar findings were reported by an Australian study which highlighted that when over the counter pharmacist-only sleep medication (Restavit) was requested in the Australian community pharmacy setting, only $30 \%$ of requests were handled entirely by the pharmacist. ${ }^{26}$ The results of the study highlighted that benzodiazepines were the most commonly given drugs and most of the remedies suggested by the dispensers were in brand names. Lexotanil囚 (bromazepam) and Lexelium ${ }^{\circledR}$ (bromazepam) were the most commonly given brands. Similar patterns of sale and use of benzodiazepines has been reported in other countries. ${ }^{17,27}$ The results of the study highlighted that the average median cost of treatment as offered by the community pharmacies was PKR10 (USD0.12). The apparent cost of treatment is low as community pharmacies offer treatment for a day or two and not provide whole regimen, which make them a quick and cheaper source of medicines for the public. $^{28}$

As pharmacist is the primary point of contact for people who request assistance with insomnia, at community pharmacy, so investigation of underlying causes of insomnia and provision of advice on lifestyle changes by him can reduce the risk of primary insomnia. ${ }^{29}$ The results of the study showed that history taking and counselling were the missing components at the community pharmacies. There was no difference in the case management of different providers at community pharmacies situated at different locations in the two cities. This might be due to low availability of qualified personnel at community pharmacies. Similar results of low history taking and counseling practices for insomnia was reported. ${ }^{26,29}$ However, the findings of the present study showed that pharmacists were

\begin{tabular}{|c|c|c|c|c|c|c|c|c|}
\hline \multirow[b]{2}{*}{ Variable } & \multicolumn{4}{|c|}{ History taking } & \multicolumn{4}{|c|}{ Provision of advice } \\
\hline & $\begin{array}{c}\text { No } \\
\text { pharmacies } \\
\text { visited }\end{array}$ & $\begin{array}{c}\text { Median } \\
\text { scale score }\end{array}$ & U & $p$ - value & $\begin{array}{c}\text { No of } \\
\text { pharmacies } \\
\text { visited }\end{array}$ & $\begin{array}{l}\text { Median } \\
\text { scale score }\end{array}$ & $U$ & $\begin{array}{c}\mathrm{p}- \\
\text { value }\end{array}$ \\
\hline \multicolumn{9}{|l|}{ Setting } \\
\hline Rural & 287 & 10 & \multirow{2}{*}{1.204} & \multirow{2}{*}{1.00} & 287 & 10 & \multirow{2}{*}{540} & \multirow{2}{*}{0.118} \\
\hline Urban & 84 & 9 & & & 84 & 10 & & \\
\hline
\end{tabular}




\begin{tabular}{|c|c|c|c|c|c|c|c|c|}
\hline Variables & $\begin{array}{c}\text { No pharmacies } \\
\text { visited }\end{array}$ & $\begin{array}{c}\text { Median } \\
\text { scale } \\
\text { score }\end{array}$ & $\mathrm{H}$ & $p$-value & $\begin{array}{c}\text { No of } \\
\text { pharmacies } \\
\text { visited }\end{array}$ & $\begin{array}{c}\text { Median } \\
\text { scale } \\
\text { score }\end{array}$ & $\mathrm{H}$ & $\begin{array}{c}p- \\
\text { value }\end{array}$ \\
\hline \multicolumn{9}{|l|}{ Cities } \\
\hline Islamabad & 118 & 9 & 3.78 & 0.149 & 118 & 9 & 17.66 & 0.230 \\
\hline \multicolumn{9}{|l|}{ Location of pharmacy } \\
\hline Near hospital & 159 & 9 & \multirow{3}{*}{0.285} & \multirow{3}{*}{0.959} & 159 & 10 & \multirow{3}{*}{4.121} & \multirow{3}{*}{0.232} \\
\hline In Supermarket & 137 & 9 & & & 137 & 10 & & \\
\hline In small market & 73 & 9 & & & 73 & 10 & & \\
\hline \multicolumn{9}{|l|}{ Type of provider } \\
\hline
\end{tabular}

more frequently involved in the process of history taking but their presence was negligible at community pharmacies. Similar results of involvement of pharmacists in responding appropriately to complaints of sleepiness in terms of eliciting insomnia type and counselling about medicines use from a study conducted in Australia reported significant improvement in sleep score outcomes. 5

The data presented above was obtained in three cities of Pakistan and can not necessarily be generalized to other parts of the country. These findings are important in giving information on the current scenario of case management at pharmacies in three cities. The use of simulated client is an effective methodology for assessing practices but use of external data collectors can create biasness in the response of the dispensers.

\section{CONCLUSIONS}

The results of the study revealed that the overall process of disease management of insomnia at community pharmacies in Pakistan is not satisfactory. The overall process of history taking and medication counselling at community pharmacies either located in rural or urban setting and irrespective of the provider type and location of pharmacies, in the three cities is inadequate. Sale of benzodiazepines without prescription is a common practice. Patients are being treated by non-qualified personnel's at community pharmacies and referral practices are limited.

\section{CONFLICT OF INTEREST}

None.

Funding Source: Partially funded by Ministry of Health, Government of Pakistan.

\section{References}

1. Sivertsen B, Krokstad S, Mykletun A, Overland S. Insomnia symptoms and use of health care services and medications: the HUNT-2 study. Behav Sleep Med. 2009;7(4):210-222. doi: 10.1080/15402000903190199

2. LeBlanc M, Mérette $\mathrm{C}$, Savard J, Ivers $\mathrm{H}$, Baillargeon L, Morin $\mathrm{CM}$. Incidence and risk factors of insomnia in a population-based sample. Sleep. 2009;32(8):1027-1037

3. Daley M, Morin CM, LeBlanc M, Grégoire JP, Savard J. The economic burden of insomnia: direct and indirect costs for individuals with insomnia syndrome, insomnia symptoms, and good sleepers. Sleep. 2009;32(1):55-64

4. Kupfer DJ, Reynolds CF 3rd. Management of insomnia. N Engl J Med. 1997;336(5):341-346.

5. Kippist C, Wong K, Bartlett D, Saini B. How do pharmacists respond to complaints of acute insomnia? A simulated patient study. Int J Clin Pharm. 2011;33(2):237-245. doi: 10.1007/s11096-011-9482-5

6. Brunette MF, Noordsy DL, Xie H, Drake RE. Benzodiazepine use and abuse among patients with severe mental illness and co-occurring substance use disorders. Psychiatr Serv. 2003;54(10):1395-1401.

7. Fuller JM, Wong KK, Krass I, Grunstein R, Saini B. Sleep disorders screening, sleep health awareness, and patient follow-up by community pharmacists in Australia. Patient Educ Couns. 2011;83(3):325-335. doi: 10.1016/j.pec.2011.05.004

8. Black J, Saini B, Wong K, The role of pharmacists in improving the management of sleep disorders in the community. Respirology, 2007;12(1):A24.

9. Stone L. Good Pharmacy Practice (GPP) in Developing Countries 1997 1997; Available from: http://www.fip.org/files/www2/pdf/gpp/GPP_CPS_Report.pdf (accesed 2009 20th November)

10. Berih AA, McIntyre L, Lynk AD. Pharmacy dispensing practices for Sudanese children with diarrhoea. Public Health. 1989;103(6):455-458.

11. Hogan R. Educating Private drug sellers. Dialogue on Diarrhoea, 1994(55):1

12. Ross-Degnan D, Soumerai SB, Goel PK, Bates J, Makhulo J, Dondi N, Sutoto, Adi D, Ferraz-Tabor L, Hogan R. The impact of face-to-face educational outreach on diarrhoea treatment in pharmacies. Health Policy Plan. 1996;11(3):308318 
13. Tawfik $Y$, Northrup R, Jones SP. Utilizing the Potential of Formal and Informal Private Practitioners in Child Survival, SARA: Washington, DC;2002.

14. Chalker J, Chuc NT, Falkenberg T, Tomson G.Private pharmacies in Hanoi, Vietnam: a randomized trial of a 2-year multi-component intervention on knowledge and stated practice regarding ARI, STD and antibiotic/steroid requests. Trop Med Int Health. 2002;7(9):803-810.

15. Oun S, Edward-Raj A, Ojuola O, Bowman G, Long WM. Assessing the quality of health services provided by informal drug sellers in rural Cambodia. in American Public Health Association 133rd Annual Meeting \& Exposition.Philadelphia, 2005. https://apha.confex.com/apha/133am/techprogram/paper_111013.htm (accessed 2009 20th November)

16. Nsimba SE. Assessing the impact of educational intervention for improving management of malaria and other childhood illnesses in Kibaha District-Tanzania. East Afr J Public Health. 2007;4(1):5-11.

17. Benjamin H, Smith F, Motawi MA. Drugs dispensed with and without a prescription from community pharmacies in a conurbation in Egypt. East Mediterranean Health J. 1996;2(3):506-514.

18. Rabbani F, Cheema FH, Talati N, Siddiqui S, Syed S, Bashir S, Zuberi LZ, Shamim A, Mumtaz Q. Behind the counter: pharmacies and dispensing patterns of pharmacy attendants in Karachi. J Pak Med Assoc. 2001;51(4):149-153.

19. Qidwai W, Krishanani MK, Hashmi S, Afridi M, Ali RA. Private Drug Sellers Education in Improving Prescribing Practices. J Coll Physicians Surg Pak. 2006;16(12):743-746.

20. Chalker JC. Interventions for improved prescribing and dispensing of medicines in Nepal, Thailand and Vietnam, in Public Health. Stockholm Karolinska Institutet: 2003.

21. Goodman CA, Mutemi WM, Baya EK, Willetts A, Marsh V. The cost-effectiveness of improving malaria home management: shopkeeper training in rural Kenya. Health Policy Plan. 2006;21(4):275-288.

22. Basak SC, Prasad GS, Arunkumar A, Senthilkumar S. An attempt to develop community pharmacy practice : Results of two surveys and two workshops conducted in tamilnadu. Indian J Pharm Sci. 2005:67(3):362-367.

23. Babar Z. Medicalising Pakistan. 2007; Available from: http://www.chowk.com/articles/11520 (accesed 2009 20th November)

24. WHO. How to Investigate Drug Use in Health Facilities Geneve;WHO:1993.

25. Israel GD. Determining sample size. University of Florida. 2007. http://edis.ifas.ufl.edu/pd006 (accessed 200920 th November)

26. Kashyap KC, Nissen LM, Smith SS, Douglas JA, Kyle GJ Can a community pharmacy sleep assessment tool aid the identification of patients at risk of sleep disorders in the community: a pilot study. Integrated Pharmacy Research and Practice, 2012;1:3-12.

27. Paredes NP, Miasso Al, Tirapelli CR. Consumption of benzodiazepines without prescription among first-year nursing students at the University of Guayaquil, school of nursing, Ecuador. Rev Lat Am Enfermagem. 2008;16(Spec No):634669.

28. Goel P, Ross-Degnan D, Berman P, Soumerai S. Retail pharmacies in developing countries: A behavior and intervention framework. Soc Sci Med. 1996;42(8):1155-1161.

29. Kashyap KC, Nissen LM, Smith S, Kyle GJ. Supply of non-prescription "pharmacist-only" doxylamine tablets in Australian community pharmacies: a simulated patient study. 21st Congress of the European Sleep Research Society. Paris. 2012. 